\title{
The Modern Aspect of Education Ecology: the Concept of Lifelong Learning in the Context of Information Society
}

\author{
Vitaly Ivlev \\ Department of Philosophy \\ Bauman Moscow State Technical University \\ Moscow, Russia \\ Financial University under the Government of Russian \\ Federation \\ (Financial University) \\ Moscow, Russia \\ E-mail: vitalijivlev@yandex.ru
}

\author{
Marina Ivleva \\ Department of history and philosophy \\ Plekhanov Russian University of economics \\ Moscow, Russia \\ E-mail: stm602@yandex.ru
}

\begin{abstract}
The article analyzes the concept of "lifelong learning" on the basis of the complexity and diversity of education as a system. The article researches the history of this concept occurrence and the specificity of its implementation in modern information society, and also examines the place of the concept in the system of ecology education, an essential element of which is the human person. Analyzing the essence of the "lifelong learning" concept, as outlined in the Memorandum of continuing education of the $\mathrm{EU}$ and in the context of the Bologna educational system, the authors produce a comparative analysis of instrumental and classical education, and draw conclusions about the necessity of fundamental and applied aspects harmonization in the system of "education of a lifetime".
\end{abstract}

Keywords-education; the concept of "lifelong learning"; information society; the environment; education; personality; basic and applied science; instrumental education; classical education

\section{INTRODUCTION}

The current stage of modern society development is often defined as the "economy of knowledge", and the institute of education as a system of training, education and formation of the worldview of people is considered as the foundation of social system. Education is an integral system that should have stability and the ability to personal self-regulation, and ecology of education is an integral part of the ecology of culture in general. Consequently, education as a system should have a fundamental component, which can form the basis of the modern educational space within the scales of continuing education concept, which was established a response to the realities of an intensively complicated scientific, technical and economic and social environment.

The multiplicity and multi-aspect character of education as a system implies the necessary consideration of a personality within its framework [1]. Personality is the starting point around which the educational process and the whole system of education is built.

\section{EVOLUTION OF THE TRADITIONAL CONCEPT OF EDUCATION IN THE INFORMATION SOCIETY}

The specific role of education in modern society is reflected in the evolution of the concept of education itself. If "classical education" aimed at the development of the student's personality, adoption a certain amount of fundamental knowledge in the sphere of natural and social sciences as the basis for future knowledge, the European summit, held in Lisbon on 23-24 March 2000, defined new benchmarks of the education system within the framework of the strategic objectives of the EU.

The outcome document of the summit concluded that Europe was faced with many changes caused by globalization and new challenges of the knowledge economy. The document noted that the qualification requirements for workers, especially in the field of information technology, are becoming higher, but there are no enough educated professionals, as a result, working places remained unoccupied in spite of the growth of unemployment. Consequently, in order to achieve the European goal of sustainable economic growth, better employment structure and social cohesion, there were formulated certain objectives, in particular, so that every citizen has the skills and abilities necessary to live and work in a new information society.

To attain such a goal, it is necessary to adapt the education system to the requirements of the informatiom society, namely, to transform education into a system of "lifelong learning".

At the meeting of the European Commission in Brussels (30.10.2000) the Memorandum on Lifelong Learning in the European Union was adopted. It defines "life-long education" as all purposeful learning activity undertaken on 
an ongoing basis with the aim of improving knowledge, skills and competence. Unlike the previous document, the sphere of continuing education was not limited to a certain target audience, but extended to all groups of the population, and the postulate of obtaining and updating knowledge during personal life became the fundamental principle of the educational system, in order to obtain equal opportunities for Europeans to adapt to socio-economic changes.

\section{A RETROSPECTIVE OF THE CONCEPT OF LIFELONG LEARNING}

It is important to emphasize that the idea of continuing education (lifelong learning), the key concept of modern education strategy, has a long history. Such ideas were expressed by ancient thinkers, in particular, Plato and Aristotle.

For example, Plato postulates the idea that the process of education should last almost the entire adult life of a person, and the stages of this process are due to age characteristics. Learning begins in childhood, at the so-called "musical" and "gymnastic" stages, when the main attention is paid to the basics of knowledge and sensory knowledge of the world, as well as physical exercises. As a teenager grows up, it is the time for a more in-depth study of theoretical knowledge in the field of fundamental sciences, such as mathematics, geometry, astronomy. In turn, math classes contribute to the development of theoretical thinking and the ability to comprehend philosophy as the highest degree of knowledge.

Aristotle, Plato's disciple, who created his own philosophical original concept, develops his teacher's views in the field of pedagogy. According to Aristotle, since the goal of education is to improve the human essence, it must accompany the person throughout his life, even after four stages of young people education, which include the following: first, it is a propaedeutic stage, devoted to the basics of reading, writing, arithmetic, drawing, gymnastics, logic are studied; second, the main stage, devoted to the knowledge of natural sciences of nature, mathematics, philosophy; third stage is the study of society, ethics and politics, and finally, it is the study of poetry and rhetoric.

Later, the idea of continuing education was formulated by European scientists and thinkers, and one of the first elements of its introduction into social practice is considered to be the workshop schools that were established in Europe in the XIII-XIV centuries.

Therefore, the concept of lifelong learning has deep historical roots. It was also adopted in the national doctrine of education in the Russian Federation (October 2000). According to this document, the strategic goals of education were closely connected with the problems of the Russian society development. Among the key tasks of education system, there were tasks of ensuring the historical continuity of generations, education of active citizens and patriots of Russia, education of a holistic and scientific worldview, continuity of education along lifetime, academic mobility of students.

\section{CLASSICAL AND INSTRUMENTAL EDUCATION: A COMPARATIVE ANALYSIS}

Therefore, the concept of continuing education is not something completely new, it was formed in the system of traditional, classical education. Traditionally, the distinctive features of higher education were the universality of knowledge, the unity of the fundamental humanities and natural sciences in the learning process, as well as the studying of applied sciences. The objective of classical education was to provide students with basic knowledge in various fields, including social and humanitarian, so that the wide range of vision determined the successful perception of the new knowledge later.

In modern information society, a classical education gives way to instrumental education. One of his adherents was Norman Tebbit, a British politician, former Chairman of the conservative party of Great Britain in 1985-87. He actively promoted the idea of instrumental education in the 80 s of the twentieth century. In his opinion, educational programs and curricula should be changed in such a way as to increase personal effectiveness and achievements in the workplace, as well as to offer students the opportunity to develop and apply certain skills, including communication skills, teamwork, leadership, decision-making, problemsolving skills, management in specific situations and risk taking. Debating with N. Tebbit in 1992, D. Bridges drew attention to the potential problems of the instrumental approach, contrasting it with a personal, "free" education, the central idea of which was to give a person the potential to make a free, autonomous choice, what kind of life he will live. Such education includes the ability to critical analysis of ideas and beliefs on the basis of objective information, and personal independence or autonomy, which gives a person the will and confidence in behavior on the basis of his own beliefs [2]. In other words, while traditional education focused primarily on the education and development of the individual as a personality, instrumental education focused on maintaining the competitiveness of the individual in the labor market.

Analyzing instrumental and classical education, and the place of fundamental and applied disciplines in the educational process, R.A.Nurullin offers to distinguish between two concepts - "civilization" and "culture". While culture is defined as a set of spiritual values accumulated by society throughout its history, civilization is largely an integral result of social relations, certain level of social development which determines the dynamics and volume of material production and consumption in society. Therefore, the civilization is concentrated on the material values, benefits and services, and promote instrumental education and brings in the first turn good professional executors [3].

\section{THE MOdERn PROBLEM OF THE UNITY OF CLASSICAL AND INSTRUMENTAL EDUCATION IN THE CONTEXT OF LONGLIFE LEARNING}

Development of culture and civilization is different, but they do not oppose to each other. Vice versa, they should be viewed in dialectical unity on the basis of the principle of 
complementarity. This requires the formation of a selforganizing structure (communication system) in society in which changes in culture and civilization would complement each other through the implementation of this task through the education system.

The increasing role of instrumental education in the modern information society is not accidental. Hollow rejection of instrumental education and a return to the classical in modern conditions is impossible. The rapid development and emergence of new techniques and technologies and their active introduction into the production process and management at various levels of the social system determine rapidly changing demands on employees. Employees should acquire new knowledge and must be flexible to changing working conditions. Globalization processes lead to the leveling of country diversity in technological production processes and the introduction of common technological operations in the world, which requires the unity of the education system in different countries, the possibility of problem-free exchange of specialists and their employment in other countries. Therefore, the emergence of the Bologna educational system historically determined. On the one hand, it introduces uniformity in the educational system, and on the other, postulates the educational process as the formation of certain competencies of the individual, but not the development of the individual as such.

However, this does not guarantee the formation of knowledge basis using which an individual will be able to continue personal studies in a certain area according to the changing conditions. But a graduate who has received a set of competencies of a certain kind, may face a situation, because of changes in technology, where he will need other competencies. Within the framework of instrumental education, he should receive a new education with a new set of competencies, since he had not been initially trained to receive new knowledge by himself, on the basis of fundamental knowledge, methodology and logical thinking. Instrumental education aimed at obtaining knowledge "here and now" rather than "everywhere and always". Producing a competent professional in a particular field, instrumental education does not give him either the wide range of possible solutions choice, or the scope of information coverage.

In modern information society we observe continuous complication of scientific knowledge structure and constant increase of its volume. In such conditions, ability to organize information and to draw conclusions using the minimum necessary data becomes very important. This important methodological principle is known as the "Occam Razor". It is determined by Aristotelian logic, namely, by "the principle of sufficient reason"[4]. The development of economic, social, intellectual tasks in the context of the information society and the digital economy involves creative and innovative approaches. The most important capital in the information society, based on knowledge, is the intellectual one. The human imagination is the main value. The innovative nature of the "electronic digital society" implies constant innovation, updating of products, processes, marketing. Therefore, various subjects in the curriculum should be presented in a balanced manner, in the structure of which it is necessary to have both a fundamental and an applied component [5], [6].

In addition, it is necessary to pay attention to another aspect of the problem of fundamental and applied subjects in the educational space of higher education. Humanitarian education, generally combining these components with the leading role of the fundamental, is the basis for the development of the student's personality [7]. Thus, knowledge of philosophy is necessary not only for philosophers, but also for specialists in different sciences - it teaches them to think logically, reasonably, evidently, bring their knowledge into the system. Knowledge of logic, as a science of correct thinking, is necessary for everyone - a theorist, a practitioner, a manager, and a scientist. Logic will help to organize ideas properly and to produce evidence to express their thoughts, to structure and design scientific research. The role of ethics is also great. The moral component in modern society, the question of the social responsibility of business in the humanization of modern society and economy, in particular, is very important.

\section{CONCLUSION}

The innovative nature of modern society requires an appropriate system of education, where students develop creative thinking and the ability to interiorize new information[8]. Such tasks, as mechanical learning of a large amount of information and its reproduction, or studying exclusively specialized knowledge, without social and humanitarian bases, should be excluded from modern education. Education, in the same time, should be both a professional training, and also a factor in human beings integration into the cultural environment of modern information society. This is facilitated by the social and humanitarian component of educational programs, which allows to realize the following functions: to include the system of values of higher education into the context of culture; to form common sense-forming constructs in the minds of students, since professional activity is included in the basic ideological attitudes; to develop multicultural attitudes of students that provide their ethno-cultural and civic competence; to develop the future specialist's communicative competence, ability to communicate with colleagues in different ethno-cultural environments.

The concept of "long life learning" is one of the important components of the education system as a whole, a concept that reveals the methodological meaning and tools of obtaining knowledge by a person. As we have shown, this concept has deep historical roots and has been implemented throughout the history of mankind. The current conditions of the information society, with a special place in its boundaries of technology and technology, have now led to the predominance of the instrumental aspect, instrumental understanding of the goals and objectives of "life-long education"[9], [10]. However, it would be a mistake to reduce a person exclusively to individual characteristics, skills and abilities, losing sight of his personal characteristics, his ability to perceive and reproduce human culture, and at the same time himself as a person. And the introduction of 
personal and educational components, which are primarily determined by the philosophical and humanitarian disciplines, the development of personality thinking, the breadth of its Outlook and the ability to perceive information as a whole, which determine the fundamental Sciences, will take the concept of "long life learning" worthy place in the ecology of education. The innovative nature of modern society requires an appropriate system of education, orientation of students not on the mechanical learning of a large amount of information and its reproduction, or to obtain highly specialized knowledge, but on the development of creative thinking and the ability to interiorize new information. Education should be not only a vocational training, but also a factor in integrating human beings into the cultural environment of the modern information society. This is facilitated by the social and humanitarian component of educational programs, which allows to realize the following functions: to include the system of values of higher education in the context of culture; to form common sense-forming constructs in the minds of students, since professional activity is included in the basic ideological attitudes; to develop multicultural attitudes of students that provide ethno-cultural and civic competence of the student; to develop the future specialist's communicative competence, ability to communicate with colleagues in different ethnocultural environments.

The concept of "lifelong learning" is one of the important components of the education system as a whole, a concept that reveals the methodological meaning and tools of obtaining knowledge by a person. As we think, this concept has deep historical roots and has been implemented in society throughout the history of mankind. The current conditions of the information society, where technology and technology play the dominant role, have determined the predominance of instrumental aspect, instrumental understanding of the goals and objectives of "lifelong education". However, it would be a mistake to reduce a person exclusively to individual working characteristics, skills and abilities. In the educational process, it is necessary to develop personal creativity, ability to perceive and reproduce human culture, and at the same time moral and intellectual characteristics. And the introduction of personal and educational components, which are primarily influenced by the philosophical and humanitarian disciplines, the development of personality thinking and the range of personal vision, and, at last, the development of ability to perceive information as a whole, as it is offered by the fundamental sciences, - all these measures will determine the concept of "lifelong learning" worthy place in the ecology of education.

\section{REFERENCES}

[1] E.Barkova, M.Ivleva,O.Buzskaya, M. Buzskij Ecology of culture in the space of social and humanitarian knowledge. In: Proceedings of the 2017 2rd International Conference on Contemporary Education, Social Sciences and Humanities 2017. C. 12-15.

[2] D. Bridges (1992), "Enterprise and liberal education", Journal of Philosophy of Education, Vol. 26 No. 1, pp. 91-98, p.93. [2] Carson R. Silent Spring / R. Carson. Boston: Houghton Mifflin. Reprinted, 1961.
[3] R.A. Nurullin.Formirovanielichnosti v polikulturnom pole global'noitzivilizatzii. In: Obrazovanie i lichnost' raznoobraziezonrazvitiz. To 120-letiju L.C.Vygotski (oktyabr' dekabr' 2016). - Kazan: NOU DPO «Tzentrsozial'nogumanitarnogoobrazovaniya», 2017, c. 81-83

[4] V.Y.Ivlev,M.L. Ivleva. Peculiarities of Aristotelian scholastic logic. In: Proceedings of the 2017 2rd International Conference on Contemporary Education, Social Sciences and Humanities 2017. C. 91-95.

[5] I.Ponizovkina, E. Agibalova. Loss of life purpose as a problem of modern society. In: Proceedings of the 2016 International Conference on Contemporary Education, Social Sciences and Humanities (ICCESSH 2016). 2016. C. 657-662.

[6] B.S.Vasyakin,M.I.Ivleva,E.L.Pozharskaya,O.I.Shcherbakova. A study of the organizational culture at a higher education institution (case study: Plekhanov Russian university of economics (PRUE)). International Journal of Environmental and Science Education. 2016. T. 11. № 18. C. 11515-11528.

[7] V.Inozemtsev,M.L.Ivleva,V.Ivlev. Artificial intelligence and the problem of computer representation of knowledge. In: Proceedings of the 2017 2rd International Conference on Contemporary Education, Social Sciences and Humanities 2017. C. 1151-1157.

[8] V.Ivlev,M.Oseledchik Methodological principles for the introduction of modality categories in modern scientific cognition. 3rd international conference on arts, design and contemporary education (ICADCE 2017). 2017. C. 541-545.

[9] M.I.Ivleva,I.V.Yablochkina,I.M.Kornilova,S.D.Lyudvig,B.S. Vasyakin Ecological aspect of investment projects for the development of specially protected nature territories (by the example of the Sochi national park) // Research Journal of Pharmaceutical, Biological and Chemical Sciences. 2016. T. 7. № 4. C. 1293-1303.

[10] M.Oseledchik,M.L.Ivleva,V. Ivlev The fractal nature of implicit knowledge. In: 3rd international conference on arts, design and contemporary education (ICADCE 2017) Moscow, Russia. 2017. C. 673-676 